\title{
Measuring economic uncertainty and its impact on the stock market
}

Dzielinski, Michal

\begin{abstract}
This paper proposes a novel measure of economic uncertainty based on the frequency of internet searches. The theoretical motivation is offered by findings in economic psychology that agents respond to increased uncertainty by intensifying their information search. The main advantages of using internet searches are broad reach, timeliness and the fact that they reflect actions, rather than words, which however are not directly related to the stock market. The search-based uncertainty measure compares well against a peer group of alternative indicators and is shown to have a significant relationship with aggregate stock returns and volatility.
\end{abstract}

DOI: https://doi.org/10.1016/j.frl.2011.10.003

Posted at the Zurich Open Repository and Archive, University of Zurich

ZORA URL: https://doi.org/10.5167/uzh-55460

Journal Article

Accepted Version

Originally published at:

Dzielinski, Michal (2012). Measuring economic uncertainty and its impact on the stock market. Finance Research Letters, 9(3):167-175.

DOI: https://doi.org/10.1016/j.frl.2011.10.003 


\section{Elsevier Editorial System(tm) for Finance Research Letters Manuscript Draft}

Manuscript Number: FRL-11-88R2

Title: Measuring economic uncertainty and its impact on the stock market.

Article Type: Regular Article

Keywords: economic uncertainty; Google Trends; information search; C22 G12 G14

Corresponding Author: Mr Michal Dzielinski,

Corresponding Author's Institution: University of Zurich

First Author: Michal Dzielinski

Order of Authors: Michal Dzielinski

Abstract: This paper proposes a novel measure of economic uncertainty based on the frequency of internet searches. The theoretical motivation is offered by findings in economic psychology that agents respond to increased uncertainty by intensifying their information search. The main advantages of using internet searches are broad reach, timeliness and the fact that they reflect actions, rather than words, which however are not directly related to the stock market. The search-based uncertainty measure compares well against a peer group of alternative indicators and is shown to have a significant relationship with aggregate stock returns and volatility. 


\title{
Measuring economic uncertainty and its impact on the stock market.
}

\author{
Michal Dzielinski ${ }^{\mathrm{a}, *}$ \\ ${ }^{a}$ Department of Banking and Finance, University of Zurich, Plattenstrasse 32, 8032 Zurich, Switzerland, tel: \\ +41446343708, fax: +41446344970, email: michal.dzielinski@bf.uzh.ch
}

\begin{abstract}
This paper proposes a novel measure of economic uncertainty based on the frequency of internet searches. The theoretical motivation is offered by findings in economic psychology that agents respond to increased uncertainty by intensifying their information search. The main advantages of using internet searches are broad reach, timeliness and the fact that they reflect actions, rather than words, which however are not directly related to the stock market. The search-based uncertainty measure compares well against a peer group of alternative indicators and is shown to have a significant relationship with aggregate stock returns and volatility.

Keywords: economic uncertainty, Google Trends, information search

JEL: C22, G12, G14
\end{abstract}

${ }^{*}$ Corresponding author 


\section{Introduction}

Numerous models in the finance literature argue that economic agents have a preference for early resolution of uncertainty and that economic uncertainty has impact on the stock market (Bansal et al. (2005), Boguth and Kuehn (2009) and Bollerslev et al. (2009) to name just a few). On the other hand, studies in economic psychology consistently find that the typical response to uncertainty is by increasing information search (see e.g. Liemieux and Peterson (2011) and the references therein). Thus, it would seem natural to measure the uncertainty of investors by analyzing their search behavior. In this paper I argue that the frequency of internet searches reported by Google Trends can be used to appropriately capture the investor uncertainty about the state of the economy and that it has implications for aggregate stock returns and volatility.

The departing point is the conjecture more uncertain investors seek information more intensively and that this can be represented by the volume of internet searches. The first part of the argument is substantiated by the psychological evidence mentioned above. The main task here is identifying the relevant subset of all possible searches. The second part has to do with the spread and centralization of internet searches. Internet penetration in developed countries now exceeds $75 \%$ of households according to www.internetworldstats.com and its role for various aspects of life but especially information exchange and retrieval is unquestionable. Willingly or not, every internet user leaves behind data on what she or he was looking for every time when using a search engine. If analyzed systematically and on a large scale, such data would be ideally suited for tracking information seeking activities in the real world environment. This has become realistic after Google revolutionized internet search technology in the late 90's, becoming the biggest search engine by June 2000, first as measured by the number of indexed pages, and soon after also by the number of users. In recent years it has consistently accounted for an estimated $70 \%$ of global search traffic. Therefore, patterns of searches obtained by Google have a serious claim on representativeness. With the launch Google Trends in 2006 this vast universe of data became publicly available. Google

BR - Barron's Confidence Index

$\mathrm{OYC}_{\text {inst }}, \mathrm{OYC}_{\text {ind }}$ - Yale School of Management Stock Market Confidence Index for institutional and individual investors respectively

ST - State Street Confidence Index

SVI - Search Volume Index from Google Trends

VP - variance premium 
Trends makes it possible to track the relative popularity of any given search term over time. The dataset goes back to 2004 and is updated weekly. It is also scaled by the total search traffic, so as to conceal the actual number of Google users, and presented in the form of a search volume index (SVI). In 2008 a sister application was launched under the name Google Insights for Search, which includes a useful extension, allowing filtering the results by category to determine e.g. what users searching for "apple" were actually interested in (two of the over 20 categories are "Computers \& Electronics" and "Food \& Drink"). Based on these two sources I construct a measure to capture the information seeking of investors and thus their degree of uncertainty.

The are two main advantages to measuring uncertainty using internet searches. The first one is the comparatively high frequency. The second one relates to the fact that the data is generated spontaneously and not by actions having directly to do with financial markets, which should limit endogeneity. One objection often raised against this kind of measures is that they can, at best, capture the behavior of individual, less sophisticated investors only. I try to address this concern directly by comparing the Google Trends measure to a peer group, which also includes indicators specifically designed with institutional investors in mind. Moreover, focusing on individual investors, even if true, does not make the measure useless. Such investors can also have a significant impact on the stock market, especially in volatile periods.

Internet search data have already found applications in the finance literature. They were used to predict sales (Choi and Varian (2009b)), jobless claims (Choi and Varian (2009a)), flu outbreaks (Dukic et al. (2009)), individual investors' demand and IPO returns (Da et al. (forthcoming)) as well as modeling volatility asymmetry (Dzielinski et al. (2011)). This paper bears most direct resemblance to Da et al. (2010) where principal component analysis is applied to a number of economy-related search terms and the resulting index is said to capture investor sentiment. Though some of the results point in the same direction, the motivation is different. By calling their index a sentiment measure, the authors necessarily imply a degree of irrationality. In my approach, an increase in searches is a symptom of increased uncertainty, which can be perfectly rational.

\section{Internet searches and economic uncertainty}

The key issue is how to filter out the relevant content of internet searches, which in the case of Google Trends boils down to selecting appropriate keywords. One thing to avoid is hindsight bias. Today it may be well-known that recession, oil price and subprime were topics of great interest to 
investors over the past few years (unreported results actually show that an indicator based on a combination of those does a pretty good job) but back in 2005 the choice would have probably been different. The problem is to find a keyword that is general and time-invariant, while maintaining sufficient relevance. The word "economy" itself seems to be a parsimonious solution. It is definitely sufficiently broad to encompass all possible sources of economic uncertainty, including the three mentioned above, and also to be time independent. On the other hand it appears specific enough to contain noise that is either relatively small or at least constant over time because it is not used to describe any other concept, whose popularity might be correlated with the one of interest (this might be the case for instance with the word "depression"). If the assumption of constant noise is correct, the trend component should represent the relevant part of information seeking. I isolate it by dividing the current value by the value of the corresponding week one year ago, which also helps deal with the observed seasonality (Figure 1a). The dynamics of this modified measure is shown in Figure 1b, it is relatively stable until mid 2007 and increases sharply afterwards. The peak coincides with the bankruptcy of Lehman Brothers, after which a gradual return to pre-crisis levels takes place. The last months of the sample show a renewed increase in the index, indicative of the sovereign debt crisis that unsettled the markets.

I also compare the year-on-year series obtained from Google Trends with the SVI for "economy" obtained from the Google Insights "Finance \& Insurance >> Investment" category. The category assignment is performed based on factors like other keywords used in the search, other searches performed before and after etc. and should reflect the context of the searches. Thus, the comparison should verify the initial intuition that year-on-year changes capture the relevant component of search dynamics for "economy". The two series indeed appear very similar and are also highly correlated ( $\rho$ $=0.57)$ though the Google Insights SVI is more volatile. Why not use the Google Insights directly in the analysis then? For one, it is somewhat less convenient to handle due to the fact that each time series is scaled to its peak (fixed at 100), so in ongoing applications rescaling would be necessary whenever a new peak appeared. More importantly, it turns out that the Google Trends year-onyear series actually significantly leads the Google Insights series with quite a large R-squared, as documented in Table 1. The likely reason is the slight shift in the weekly time window used for computing the SVI values, which is Monday-Sunday for GT and Sunday-Saturday for GI. Therefore, the Sunday, which still contributes to the current week for GT is already part of the next week for GI. Therefore, while acknowledging the important corroboration provided by Google Insights, I only 
refer to the Google Trends year-on-year SVI for "economy" $\left(\mathrm{GT}_{\text {econ }}\right)$ in further analysis.

There are two other options in the data presentation, which are important to mention here. The first one is the regional filter, based on the origin of the query determined from the user's IP address. For the initial analysis I use the S\&P500 as the financial universe and to limit the confounding influence of searches from parts of the world unrelated to the US stock market, I only consider those originating in the US itself. This is admittedly a crude way to deal with the problem, as it implicitly assumes that only domestic investors impact the stock market. However, it is not a significant limitation in practice since the global SVI for "economy" does not fundamentally differ from the US one. The other, more important, option concerns how the data are scaled, either to a fixed or relative reference frame. The first approach applies the average search traffic in a fixed time period (generally January 2004) as a benchmark value, while otherwise the average for the whole specified time period is used. This aspect is again important in the context of the hindsight bias, since the average for the whole period is something known only at the end. Therefore, I always use fixed scaling.

I compare the measure derived from search volume to other measures of uncertainty or confidence, which are available at least at monthly frequency. The expectation is to see a positive correlation with the former and a negative correlation with the latter type. Based on their methodology, those other measures can be put into one of two groups. The first group aims to investigate investors' opinions directly, by means of a survey. A prime example is the "One-year confidence index" published every month by the Yale School of Management, based on a sample of US institutional (pension fund managers) and wealthy individual investors. The index reflects the fraction of participants expecting a strictly positive return on the Dow Jones Industrial Average over the following 12 months averaged over a rolling window of six months. It is calculated separately for institutional and individual investors.

All other measures fall into the second group and employ some kind of measure of market activity to proxy for uncertainty or confidence. The most famous is probably the VIX index of implied volatility, often described as "investors' fear gauge". Another example is the Barron's Confidence Index, defined as the ratio of yields on high vs medium grade corporate bonds with higher values (i.e. tighter spreads) indicating higher confidence. A different approach is taken by State Street, the world's biggest institutional custodian. Using unique data on asset flows it defines a proprietary confidence index, whereby shifts in institutional holdings towards riskier assets indicate 
rising confidence. In the finance literature, an interesting measure was developed by Bollerslev et al. (2009). It is based on the spread between forward-looking implied variance (derived from the VIX) and backward-looking realized variance. The higher this so-called variance premium (VP), the higher the uncertainty.

The survey-based measures deserve praise for directness but they are often criticized for limited scale (sample size) and possible problems with the honesty of the answers. On the other hand, the market-based measures are based on actions (this argument is especially underscored by State Street) and have a large scale but these actions are likely to be affected by many factors other than the one in question. $\mathrm{GT}_{\text {econ }}$ seems to connect the best of both: it is direct yet based on actions rather than statements, so honesty is not an issue and the scale is virtually unlimited.

Table 2 presents summary statistics of all the measures as well as correlations between them. Only two of the measures from the $\mathrm{GT}_{\text {econ }}$ peer group are readily available at the weekly frequency, so I also compute the monthly $\mathrm{GT}_{\text {econ }}$ for reference. It is aggregated from weekly values by taking simple averages. Whenever a week is split, it is included in the later month. The two One-year confidence (OYC) indices and the State Street (ST) confidence index are taken directly from the websites of their respective providers. The Barron's (BR) confidence index is approximated using the ratio of yields on Moody's Aaa and Baa corporate bond indices obtained from Bloomberg. I also compute monthly averages of the weekly values to compare with other measures. Weekly and monthly values of the VIX index are from Datastream. Finally, I am grateful to Hao Zhou for making the monthly variance premium data available online. The sample period is Jan 2005 - Jun 2011, except the variance premium, which is available through Dec 2010.

The most volatile measure is the variance premium (mostly because of extreme values registered during the peak of the financial crisis) followed by the VIX and $\mathrm{GT}_{\text {econ }}$. Other measures fluctuate comparatively little. The correlations first of all generally confirm that it is justified to consider confidence as the opposite of uncertainty because the two types of measures are consistently negatively correlated with each other. Furthermore, the correlations support $\mathrm{GT}_{\text {econ }}$ as a reasonable measure of uncertainty. It is positively and significantly correlated with all other measures of uncertainty, as well as significantly and negatively correlated with two of the three measures of confidence. The only exception is $\mathrm{OYC}_{\text {inst }}$ and the initial reaction might be to say this means that Google Trends has relevance for the behavior of individual but not institutional investors. However, the two measures of institutional confidence $\left(\mathrm{OYC}_{\text {inst }}\right.$ and $\left.\mathrm{ST}\right)$ are also virtually uncorrelated with each other. One way 
to explain this puzzling fact is the discrepancy between words and deeds mentioned before. However, even assuming both measures yield honest results it is possible that institutional investors remain confident about the long term outlook, captured by the OYC measure, while being uncertain right now, as depicted in current portfolio flows underlying the State Street index. This would also explain why the $\mathrm{GT}_{\text {econ }}$ measure is positively correlated with $\mathrm{OYC}_{\text {inst }}$. For individual investors, both short and long term would seem to be tied together (no correlation of $\mathrm{OYC}_{\text {ind }}$ with $\mathrm{OYC}_{\text {inst }}$, significant and positive with ST) which is consistent with them following a simpler, extrapolative market heuristics. In this context, the correlations between $\mathrm{GT}_{\text {econ }}$ and the three measures of confidence lend further support to saying that $\mathrm{GT}_{\text {econ }}$ captures uncertainty of both types of investors.

To confirm the initial findings, I regress aggregate stock returns on changes in the uncertainty measure. Using changes captures short-term fluctuations in uncertainty (Figure 1c), which should affect short-term returns. The regression is performed on weekly basis and includes changes in the two other measures of uncertainty available weekly and the past return as control variables:

$$
\operatorname{Ret}_{t}=\beta_{0}+\beta_{1} \cdot \Delta G T_{e c o n, t-1}+\beta_{2} \cdot \Delta B R_{t-1}+\beta_{3} \cdot \Delta V I X_{t-1}+\beta_{4} \cdot \operatorname{Ret}_{t-1}+\epsilon_{t}
$$

The Google search frequencies are measured on a Monday-to-Sunday basis, which is consistent with investors using information from the weekend during the following week. To avoid overlaps during the weekends, returns are calculated Monday-to-Monday using opening prices of the S\&P500 index. The significance of $\widehat{\beta}_{1}$ in Table 3 shows that internet searches do indeed have some exogenous merit in measuring economic uncertainty or otherwise their impact would have been subsumed by the VIX. This result is consistent with the findings of Da et al. (2010). The economic impact is also large - a one standard deviation change in the index is associated with a drop in the weekly return of around $0.65 \%$.

One concern relates to $\widehat{\beta}_{1}$ 's negative sign, which seems to run counter to what is generally postulated as the impact of uncertainty, namely to increase future (expected) returns as investors demand an uncertainty premium. However, increasing expected returns requires an adjustment period in which prices have to fall, resulting in negative returns. $\Delta G T_{\text {econ }}$ could capture this adjustment thanks to its comparatively high frequency. An indication that this is the case is given by the fact that the initial negative returns appear to reverse in week $t+1$.

A much clearer relationship emerges between $\Delta G T_{\text {econ }}$ and future realized volatility. Daily values 
of realized volatility for the S\&P500 index, computed from high frequency returns, are taken from Oxford-Man Institute's Realized Library. At the time of writing the downloadable dataset ends in February 2009. Weekly values are computed simply as the sum of the daily values within a given week. To control for persistence, first differences of logged weekly values are used in the regression, the right hand side is exactly as in Eq. 1. Consistent with the adjustment argument, volatility is high in the week following an increase in uncertainty and dies down in the week after that. The effect is especially remarkable given that it is not neutralized by implied volatility. Tracking internet searches would thus appear as a complimentary way to capture the uncertainty of those (probably less sophisticated) investors who do not have access to the options market but can still affect the behavior of equity indices.

The second concern is about the impact of the financial crisis, which covers a significant part of the sample period. To investigate it, I expand Eq. 1 by a dummy variable indicating the crisis period and also interact it with all other variables, particularly $\Delta G T_{\text {econ }}$ to see how much they are affected. The regression equation therefore becomes:

$$
\operatorname{Ret}_{t}=\beta_{0}+\beta_{1} \cdot \Delta G T_{\text {econ }, t-1}+\beta \cdot \text { Controls }+\gamma_{0} \cdot Z+\gamma_{1} \cdot Z \cdot \Delta G T_{\text {econ }, t-1}+\gamma \cdot Z \cdot \text { Controls }+\epsilon_{t}
$$

where:

$$
Z= \begin{cases}1 & \text { between May } 2007 \text { and June } 2009 \\ 0 & \text { otherwise }\end{cases}
$$

The dates of the financial crisis are necessarily chosen arbitrarily, since there is no consensus when exactly the crisis happened, or in fact whether it is still happening. On one hand, the chosen dates reflect the period of extreme fluctuations of all variables, which is most likely to skew the regression results towards significance. On the other hand, shifting the starting and end points by several months does not change the conclusions (not reported).

Panel B of Table 3 gives evidence that the explanatory power of the uncertainty measure for future returns is indeed much higher during the financial crisis. This is understandable given that uncertainty is likely to be at its highest (and most influential) during periods of market turmoil. It is also when an indicator of uncertainty is most useful. The relationship to future volatility is by contrast virtually unaffected by the crisis, especially at the shorter horizon. Especially this finding 
gives further support to measuring economic uncertainty based on search behavior.

The global reach of internet and Google's search engine makes an international comparison compelling. Following the structure of the regional filter in Google Trends it is based on search volume for countries and the most popular indices of the respective stock exchanges. The problem of considering only domestic investors is likely to become more severe for smaller, open exchanges and a better idea for future applications could be to take an average of the SVIs from different countries weighted by the presence investors from those countries have on that stock exchange. However, domestic investors should also account for part of the variation in returns, so as a first validity check for using internet searches to measure uncertainty in different countries this crude approach is sufficient.

Another issue, specific to the regional analysis, is language. The Google Trends interface does include a breakdown of the search volume by languages but this is misleading as it only relates to the language version of the Google site where the query was initiated and not the language of the query itself. For instance the resulting SVI for "economy" for Germany and with language set to German only reflects the fact that some users in Germany went to google.de (rather than google.com) and searched for "economy" from there. However, comparing search volumes reveals that German users searching for "economy" are just a small fraction of those using the German equivalent term "Wirtschaft". Therefore, to maintain representativeness I use the local language equivalent (also for Japan).

Results in Table 4 offer moderate support to the usefulness of the $\mathrm{GT}_{\text {econ }}$ measure across countries especially with respect to volatility and in times of economic turbulence. The latter is not necessarily a big drawback because that is also when uncertainty itself is most influential. The magnitude of the estimated parameters is always larger for the crisis period but the estimates are also very noisy. This might on one hand reflect lower precision of Google search data for those countries or the fact that investors in those countries search for something else than "economy" or its direct translation. In the case of UK, which is the only country with no significant relationship at all, it might also reflect the relatively large involvement of foreign investors in that market.

\section{Conclusions}

The results of this study successfully establish a novel measure of uncertainty about the state of the economy, based on the volume of internet searches for the word "economy". The main appeal of 
using internet searches is that they are generated through the spontaneous behavior of agents and so have interesting signalling properties. The underlying intuition derived from economic psychology is that a higher level of uncertainty about the economy increases the demand for information, which should be reflected in higher volume of internet searches with economy as their topic. Consistent with this intuition, the volume of searches for "economy" increases after the beginning of the subprime crisis, peaks around the collapse of Lehman Brothers and decreases until mid 2011. It is positively correlated with alternative measures of uncertainty and negatively with measures of investor confidence, both individual and institutional. It also appears to capture the financial impact of uncertainty in a very timely fashion. In the week following an increase in uncertainty aggregate stock returns are low but reverse in the week after. Conversely, realized volatility is high in the week after the increase and subsides in the next week. Both findings are robust and consistent with a scenario in which investors react to uncertainty first by selling risky assets and demanding a risk premium afterwards.

\section{Acknowledgements}

I am especially indebted to Marc Oliver Rieger for making me aware of existence of Google Trends. Comments from Bernard Dumas, Elise Paysan and other participants of the 2009 FINRISK Workshop at Gerzensee were very helpful in the early stages of this research, while those from Urs Schweri, Sven Christian Steude and Eliza Wu greatly contributed to its current version. The supervision provided by Thorsten Hens was very valuable throughout. The financial support from "LGT and Science" is gratefully acknowledged. Part of this research has been carried out within the National Centre of Competence in Research "Financial Valuation and Risk Management" (NCCR FINRISK). The NCCR FINRISK is a research instrument of the Swiss National Science Foundation. As always, I honor my parents for bringing me to where I am now.

\section{References}

Bansal, R., Khatchatrian, V., Yaron, A., 2005. Interpretable asset markets? European Economic Review 49, 531-560.

Boguth, O., Kuehn, L., 2009. Consumption volatility risk. In: EFA Bergen Meetings Paper.

Bollerslev, T., Tauchen, G., Zhou, H., 2009. Expected stock returns and variance risk premia. Review of Financial Studies 22 (11), 4463-4492.

Choi, H., Varian, H., 2009a. Predicting initial claims for unemployment benefits. Google Inc.

Choi, H., Varian, H., 2009b. Predicting the present with Google Trends. Google Inc.

Da, Z., Engelberg, J., Gao, P., 2010. The sum of all FEARS - investor sentiment and asset prices. Working Paper.

Da, Z., Engelberg, J., Gao, P., forthcoming. In search of attention. Journal of Finance.

Dukic, V., Lopes, H., Polson, N., 2009. Tracking flu epidemics using Google flu trends and particle learning. SSRN Working Paper.

Dzielinski, M., Rieger, M., Talpsepp, T., 2011. Volatility asymmetry, news and private investors. In: News Analytics in Finance Handbook. John Wiley \& Sons, Chichester.

Liemieux, J., Peterson, R., 2011. Purchase deadline as a moderator of the effects of price uncertainty on search behavior. Journal of Economic Psychology 32 (1), 33-44. 
Table 1:

Comparison of the two internet search-based uncertainty measures. GT $_{\text {econ }}$ is the year-to-year Google Trends index of the search volume for "economy" in the US. GI econ $_{\text {en }}$ is the Google Insights index of the search volume for "economy" in the US, restricted to the "Finance\&Insurance >> Investment" category. In the vector auto-regression analysis, each row represents the equation for the respective variable with the constant and lagged parameters given in columns. The sample period is Jan 2005 to Jun 2011.

\begin{tabular}{|c|c|c|c|c|c|c|}
\hline \multicolumn{7}{|c|}{ Panel 1: descriptive statistics } \\
\hline & Mean & Std. dev. & Correlation & & & \\
\hline $\mathrm{GT}_{\text {econ }}$ & 0.99 & 0.27 & \multirow{2}{*}{0.57} & & & \\
\hline $\mathrm{GI}_{\text {econ }}$ & 0.17 & 0.10 & & & & \\
\hline \multicolumn{7}{|c|}{ Panel 2: VAR analysis } \\
\hline & $\begin{array}{l}\text { Const. } \\
\text { (t-stat) }\end{array}$ & $\begin{array}{c}\mathrm{GT}_{\text {econ, } t-1} \\
\quad \text { (t-stat }\end{array}$ & $\begin{array}{l}\mathrm{GI}_{\text {econ,t-1 }} \\
\quad \text { (t-stat) }\end{array}$ & $\begin{array}{l}\mathrm{GT}_{\text {econ, } t-2} \\
\text { (t-stat) }\end{array}$ & $\begin{array}{c}\mathrm{GI}_{\text {econ,t-2 }} \\
\text { (t-stat) }\end{array}$ & $\operatorname{adj} .-R^{2}(\%)$ \\
\hline $\mathrm{GT}_{\text {econ }}$ & $\begin{array}{c}0.06^{* *} \\
(2.53)\end{array}$ & $\begin{array}{c}0.78^{* * * *} \\
(14.2)\end{array}$ & $\begin{array}{c}-0.04 \\
(-0.38)\end{array}$ & $\begin{array}{l}0.13^{*} \\
(1.81)\end{array}$ & $\begin{array}{l}0.20^{*} \\
(1.72)\end{array}$ & 86.0 \\
\hline $\mathrm{GI}_{\text {econ }}$ & $\begin{array}{l}-0.01 \\
(-0.78)\end{array}$ & $\begin{array}{c}0.19^{* * *} \\
(6.40)\end{array}$ & $\begin{array}{c}0.59^{* * *} \\
(10.9)\end{array}$ & $\begin{array}{c}-0.09^{* *} \\
(-2.45)\end{array}$ & $\begin{array}{c}0.14^{* *} \\
(2.19)\end{array}$ & 69.0 \\
\hline
\end{tabular}

Table 2:

Internet search-based uncertainty measure in the context of other measures of uncertainty or confidence. ${ }^{*}$ denotes significance at $5 \%$ level.

\begin{tabular}{|c|c|c|c|c|c|c|c|c|c|c|}
\hline & \multicolumn{7}{|c|}{ Uncertainty measures } & \multicolumn{3}{|c|}{ Confidence measures } \\
\hline & \multicolumn{3}{|c|}{ weekly } & \multicolumn{4}{|c|}{ monthly } & & & \multirow[b]{2}{*}{ ST } \\
\hline & $\mathrm{GT}_{\text {econ }, w}$ & $\mathrm{BR}_{w}$ & $\operatorname{VIX}_{w}$ & $\mathrm{GT}_{\text {econ, } m}$ & $\mathrm{BR}_{m}$ & $\mathrm{VIX}_{m}$ & VP & $\mathrm{OYC}_{\text {inst }}$ & $\mathrm{OYC}_{\text {ind }}$ & \\
\hline \multicolumn{11}{|c|}{ Panel A: summary statistics } \\
\hline Mean & 0.99 & 1.23 & 21.34 & 0.98 & 1.23 & 21.62 & 19.79 & 79.00 & 79.26 & 103.95 \\
\hline Std. dev. & 0.27 & 0.12 & 11.38 & 0.27 & 0.12 & 11.60 & 31.85 & 3.93 & 4.67 & 9.18 \\
\hline \multicolumn{11}{|c|}{ Panel B: correlation matrix } \\
\hline & 1.00 & $\begin{array}{c}0.38^{*} \\
1.00\end{array}$ & $\begin{array}{c}0.55^{*} \\
0.78^{*} \\
1.00\end{array}$ & 1.00 & $\begin{array}{c}0.53^{*} \\
1.00\end{array}$ & $\begin{array}{c}0.59^{*} \\
0.69^{*} \\
1.00\end{array}$ & $\begin{array}{c}0.35^{*} \\
0.10 \\
0.50^{*} \\
1.00\end{array}$ & $\begin{array}{c}0.24^{*} \\
0.06 \\
0.11 \\
0.04 \\
1.00\end{array}$ & $\begin{array}{c}-0.51^{*} \\
-0.43^{*} \\
-0.62^{*} \\
-0.25^{*} \\
0.03 \\
1.00\end{array}$ & $\begin{array}{c}-0.40^{*} \\
-0.37^{*} \\
-0.59^{*} \\
-0.31^{*} \\
-0.05 \\
0.45^{*} \\
1.00\end{array}$ \\
\hline
\end{tabular}


Table 3:

Results of regressing aggregate market returns and volatility on the changes in the uncertainty measure. The dependent variable is the return on the $\mathrm{S} \% \mathrm{P} 500$ index in week $t$ and $t+1$ and the respective weekly realized volatility. The impact of the financial crisis is also considered. $t$-statistics are computed using the Newey-West correction for up to 4 lags. ${ }^{*},{ }^{* *}$ and ${ }^{* * *}$ denote significance at the $10 \%, 5 \%$ and $1 \%$ level respectively.

\begin{tabular}{|c|c|c|c|c|c|c|c|c|}
\hline \multicolumn{9}{|c|}{ Panel A: unconditional results } \\
\hline & \multicolumn{2}{|c|}{$\operatorname{Ret}_{t}$} & \multicolumn{2}{|c|}{$\operatorname{Ret}_{t+1}$} & \multicolumn{2}{|c|}{$\Delta R V_{t}$} & \multicolumn{2}{|c|}{$\Delta R V_{t+1}$} \\
\hline$\Delta G T_{t-1}$ & \multicolumn{2}{|c|}{$\begin{array}{c}-0.0604^{* * *} \\
(-3.12)\end{array}$} & \multicolumn{2}{|c|}{$\begin{array}{c}0.0097 \\
(0.38)\end{array}$} & \multicolumn{2}{|c|}{$\begin{array}{l}1.18^{* * *} \\
(5.50)\end{array}$} & \multicolumn{2}{|c|}{$\begin{array}{l}-0.63^{* *} \\
(-2.19)\end{array}$} \\
\hline No. obs. & \multicolumn{2}{|c|}{338} & \multicolumn{2}{|c|}{337} & \multicolumn{2}{|c|}{216} & \multicolumn{2}{|c|}{215} \\
\hline Adj. $R^{2}(\%)$ & \multicolumn{2}{|c|}{6.1} & 0 & & \multicolumn{2}{|c|}{19.9} & \multicolumn{2}{|c|}{2.8} \\
\hline \multicolumn{9}{|c|}{ Panel B: conditioning on the financial crisis } \\
\hline & $Z=0$ & $Z=1$ & $Z=0$ & $Z=1$ & $Z=0$ & $Z=1$ & $Z=0$ & $Z=1$ \\
\hline$\Delta G T_{t-1}$ & $\begin{array}{c}-0.0194 \\
(-1.33)\end{array}$ & $\begin{array}{c}-0.0807^{* * *} \\
(-3.29)\end{array}$ & $\begin{array}{c}-0.0237 \\
(-1.35)\end{array}$ & $\begin{array}{c}0.0276 \\
(0.80)\end{array}$ & $\begin{array}{l}1.21^{* *} \\
(2.94)\end{array}$ & $\begin{array}{c}1.14^{* * *} \\
(4.69)\end{array}$ & $\begin{array}{c}-0.55 \\
(-0.86)\end{array}$ & $\begin{array}{c}-0.65^{* *} \\
(-2.02)\end{array}$ \\
\hline No. obs. & 113 & 225 & 113 & 224 & 121 & 95 & 120 & 95 \\
\hline Adj. $R^{2}(\%)$ & \multicolumn{2}{|r|}{8.4} & \multicolumn{2}{|c|}{1.4} & \multicolumn{2}{|c|}{19.5} & \multicolumn{2}{|c|}{3.6} \\
\hline
\end{tabular}

Table 4:

Comparing the impact of the weekly changes in the uncertainty measure across countries. $t$-statistics are computed using the Newey-West correction for up to 4 lags. ${ }^{*}, * *$ and ${ }^{* * *}$ denote significance at the $10 \%, 5 \%$ and $1 \%$ level respectively.

\begin{tabular}{|c|c|c|c|c|c|}
\hline & Australia & Canada & UK & Germany & Japan \\
\hline \multicolumn{6}{|c|}{ Returns } \\
\hline $\mathrm{Z}=0$ & $\begin{array}{c}-0.0215^{* *} \\
(-2.20)\end{array}$ & $\begin{array}{l}-0.0057 \\
(-0.67)\end{array}$ & $\begin{array}{c}-0.0005 \\
(-0.07)\end{array}$ & $\begin{array}{c}-0.0106 \\
(-0.89)\end{array}$ & $\begin{array}{c}-0.0454^{* *} \\
(-2.39)\end{array}$ \\
\hline $\mathrm{Z}=1$ & $\begin{array}{c}-0.0333^{* *} \\
(-1.95)\end{array}$ & $\begin{array}{l}-0.0418 \\
(-1.41)\end{array}$ & $\begin{array}{l}-0.0695 \\
(-1.27)\end{array}$ & $\begin{array}{l}-0.0244 \\
(-0.79)\end{array}$ & $\begin{array}{l}-0.1202 \\
(-1.36)\end{array}$ \\
\hline No. obs. & 339 & 339 & 339 & 339 & 339 \\
\hline Adj. $R^{2}(\%)$ & 3.7 & 2.6 & 7.1 & 4.7 & 4.8 \\
\hline \multicolumn{6}{|c|}{ Realized volatilities } \\
\hline $\mathrm{Z}=0$ & $\begin{array}{c}0.47 \\
(1.27)\end{array}$ & $\begin{array}{c}0.35^{* *} \\
(2.01)\end{array}$ & $\begin{array}{c}-0.05 \\
(-0.11)\end{array}$ & $\begin{array}{c}0.86^{* * *} \\
(2.32)\end{array}$ & $\begin{array}{c}0.14 \\
(0.25)\end{array}$ \\
\hline $\mathrm{Z}=1$ & $\begin{array}{c}-0.13 \\
(-0.39)\end{array}$ & $\begin{array}{c}1.00^{* *} \\
(2.23)\end{array}$ & $\begin{array}{c}0.66 \\
(1.52)\end{array}$ & $\begin{array}{c}1.31^{* *} \\
(2.22)\end{array}$ & $\begin{array}{l}2.81^{* * *} \\
(3.58)\end{array}$ \\
\hline No. obs. & 216 & 216 & 216 & 216 & 216 \\
\hline Adj. $R^{2}(\%)$ & 15.3 & 9.8 & 12.2 & 16.8 & 15.7 \\
\hline
\end{tabular}


Click here to download high resolution image

\section{SVI for "economy" (GT)}

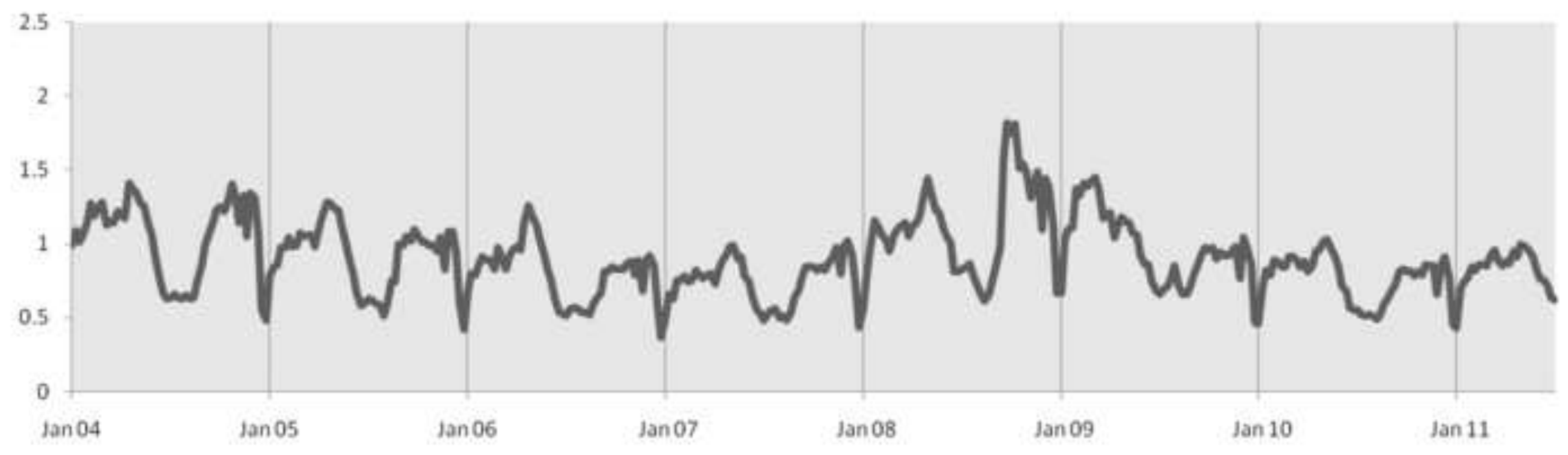




\section{Year-over-year SVI for "economy" (GT)}

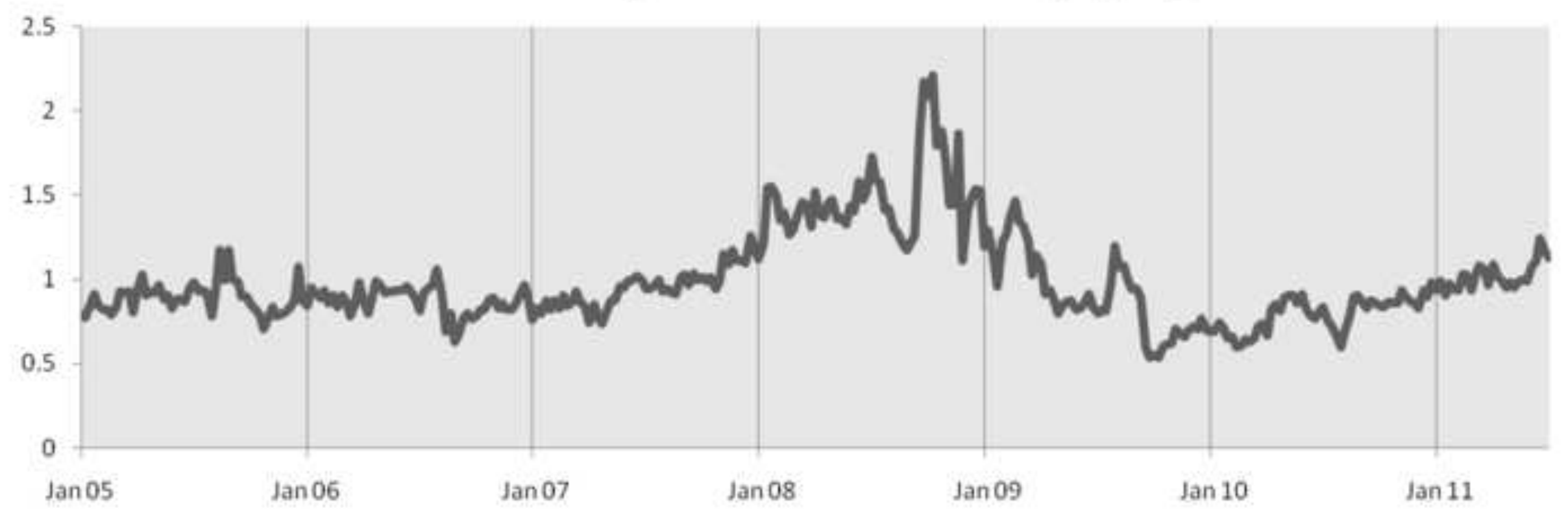


Weekly changes in the year-on-year SVI for "economy" (GT)

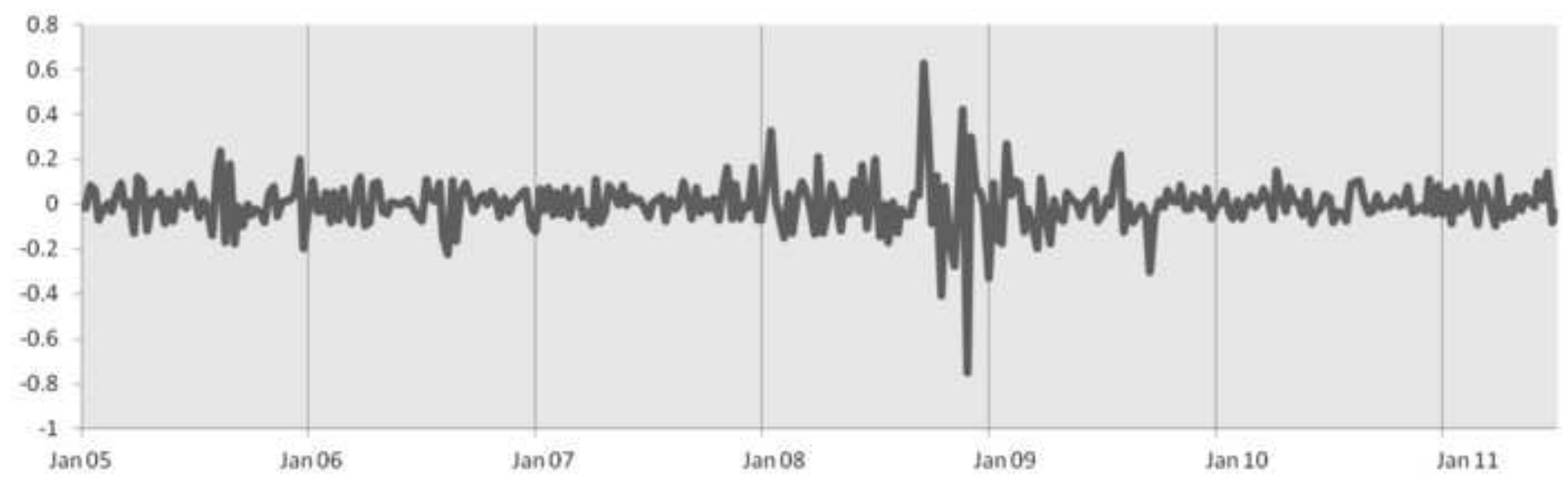

